\title{
Serological profile of febrile rash in patients at a tertiary care hospital in Telangana
}

\author{
Sultana A. ${ }^{1}$, M.L. Kavitha Latha ${ }^{2}$ \\ ${ }^{1}$ Dr. Afroze Sultana, Post Graduate, Osmania Medical College, Hyderabad, Telangana, ${ }^{2}$ Dr. M.L. Kavitha Latha, \\ Assistant Professor, Department of Microbiology, Gandhi Medical College, Secunderabad, Telangana, India. \\ Corresponding Author: Dr. M.L. Kavitha Latha, Assistant Professor, Department of Microbiology, Gandhi Medical \\ College, Secunderabad, Telangana. E-mail: resdoc555@gmail.com
}

\begin{abstract}
Introduction: Evaluating the patients who presents with fever and rash can be challenging because the differential diagnosis is extensive and includes minor and life-threatening illnesses. Materials \& Methods: A total of 300 patients with provisional diagnosis of acute febrile illness were evaluated during the period of August 2016 to July 2017 at Sir Ronald Ross Institute of Tropical and Communicable Diseases, Nallakunta, Hyderabad. All the clinically suspected cases of febrile rash were subjected for serological study. Results: Most commonly affected age group is $14-40$ years. Fever is the most common symptom. NSlag was detected in $44.7 \%$ of cases. Secondary dengue infection is $12.3 \%$. IgM is positive in $57.1 \%$ of chikungunya cases. The chicken pox IgM positivity was reported in $80 \%$ of cases. About $82.8 \%$ of measles serologically confirmed cases. Conclusion: Diagnosis can be established serologically in $63.6 \%$ of cases there by emphasizing the need for Clinico-serological correlation of rashes. Acute febrile illness comprises infection due to malaria, influenza, leptospirosis, scrub typhus, typhoid fever, and dengue, of which some infections necessitate specific treatment. As antibiotics will be required to treat bacterial diseases, knowing the viral etiology will help in avoiding unnecessary administration of antibiotics.
\end{abstract}

Key words: Fever, Rash, Serology, Age

\section{Introduction}

Evaluating the patients who presents with fever and rash can be challenging because the differential diagnosis is extensive and includes minor and lifethreatening illnesses [1].

In recent times, with increased travel and population movements imported Infections with secondary local transmission are of great concern. Viral exanthems are by far the most common cause off ever Viral exanthems are by far the most common cause off ever. There are number of viruses causing cutaneous manifestations. Rubeolaor measles caused by paramyxo virus, a major public health problem with significant mortality and morbidity in developing countries.

Febrile rashes are classified in to maculopapular rash, generalized diffuseerythema, and vesicular, pustular, nodular, petechial, and purpuric rashes [2]. Currently, viral exanthems are by far the most common cause off ever with rashin children.

Manuscript received: $11^{\text {th }}$ November 2018

Reviewed: $18^{\text {th }}$ November 2018

Author Corrected: $24^{\text {th }}$ November 2018

Accepted for Publication: $30^{\text {th }}$ November 2018
Morphological patterns, seasonal occurrence, and the presence of type of exanthema can help the physician smake a clinical diagnosis, which when confirmed by specific diagnostic tests, ensures timely and appropriate treatment, avoiding unnecessary therapy. The present study is taken upto evaluate the role of serological investigations in establishing the cause off ebrile rash

\section{Materials and Methods}

The study was conducted at Department of Microbiology, Sir Ronald Ross Institute of Tropical and Communicable diseases (SRRIT \& CD) over a period of one year from August 2016 to July 2017. A total of 300 cases of Fever with Rash are included in the study. An informed consent was obtained.

All Patients underwent minimum diagnostic work up along with serological tests. Institute's ethics committee approval was taken.

Inclusion criteria: Patients o fall ages presenting with acute fever and a rash. 


\section{Original Research Article}

\section{Exclusion criteria}

1. Patients presenting with fever of long duration.

2. Clinically diagnosed drug induced fever with rash.

3. Patient not willing to give consent.

\section{Serological tests for febrile rashes}

IgM Elisa for dengue fever:

1. IgM ELISA kit for Dengue was procured from NIV DEN MAC ELISA Kit (Version No 2.4) NIV, Pune. The sensitivity and the specificity of the test are $98.5 \%$ and $98.84 \%$ respectively.
2. IgMELISAkit for Measles was procured from Euroimmun diagnostics (Order No. EI 2610-9601 M) The sensitivity and specificity of the test are $100 \%$ and $98 \%$ respectively.

3. IgM ELISA kit for Chickunguniya was procured from NIV CHIK MAC ELISA Kit (Version No 3.4) NIV, Pune. The sensitivity and the specificity of the test are $95 \%$ and $98 \%$ respectively.

4. IgMELISAkit for VZV was procured from Euroimmun diagnostics. The sensitivity and specificity of the test are $100 \%$ and $100 \%$ respectively.

\section{Results}

A total of 300 patients with provisional diagnosis of acute febrile illness were evaluated during the period of August 2016 to July 2017 at Sir Ronald Ross Institute of Tropical and Communicable Diseases, Nallakunta, Hyderabad.

All the clinically suspected cases of febrile rash were subjected for serological study.

Most commonly affected age group is 14-40 years (Table.1) Clinical manifestations of patients with a clinically suspected cases of acute fever with rash. (Table2) Most common symptom was fever followed by rash.

Table-1: Age and sex -wise distribution of cases

\begin{tabular}{|c|c|c|c|c|}
\hline S. No & Age (years) & \% of cases & Male & Female \\
\hline 1 & $<5$ & 16.0 & 22 & 26 \\
\hline 2 & $6-13$ & 30.0 & 40 & 50 \\
\hline 3 & $14-40$ & 44.0 & 75 & 8 \\
\hline 4 & $41-60$ & 10.0 & 22 & 57 \\
\hline
\end{tabular}

Table-2: Clinical manifestation of suspected cases with febrile rash.

\begin{tabular}{|c|c|c|c|}
\hline S. No & Clinical feature & Number n (300) & Percentage (\%) \\
\hline 1 & Fever & 277 & 92.3 \\
\hline 2 & Rash & 212 & 70.6 \\
\hline 3 & Headache & 100 & 33.3 \\
\hline 4 & Body pains & 159 & 53.0 \\
\hline 5 & URTI's & 94 & 31.3 \\
\hline 6 & LRTI's & 41 & 13.6 \\
\hline 7 & Vomiting & 120 & 40.0 \\
\hline 8 & Diarrhoea & 94 & 31.3 \\
\hline
\end{tabular}

Febrile rash with seropositivity was more in measles $(82.8 \%)$ followed by chickenpox (80\%). Among dengue and chikungunya cases fever $(100 \%)$ was the most common symptom followed by arthralgia $(97.3 \%, 93.8 \%)$ respectively. Among measles \& chicken pox cases most common symptom was rash (100\%) followed by fever (98\%).

Routine diagnostic work-up included complete blood picture, Erythrocyte sedimentation rate, Platelet count. Anaemia was observed in $30 \%$ of cases, leucopenia $10 \%$, thrombocytopenia $5 \%$, leucocytosis $18 \%$, elevated liver enzymes in $7 \%$ cases. Complete urine examination did not reveals any abnormality.

Seropositive cases for Leptospirosis and Rickettsial diseases, did not present with rashes. None of the samples gave the positive results for typhoid fever 
Original Research Article

Table-2: Data showing serologically confirmed cases of fever with rash

\begin{tabular}{|c|c|c|}
\hline S.No. & Disease & No. of positive cases (\%) \\
\hline 1 & Dengue & $63(21)$ \\
\hline 2 & Chickunguniya & $28(9.3)$ \\
\hline 3 & Measles & $36(21)$ \\
\hline 4 & Chickenpox & $36(12)$ \\
\hline
\end{tabular}

A total of $43.7 \%$ (NS1) of the samples were from acute phase serum samples and $48.1 \%$ (IgM) and $12.3 \%$ (both IgM \& $\mathrm{IgG})$ were from early convalescent phase out of 49 cases of Chikungunya- 28 cases $(57.1 \%)$ were positive, out of 76 cases of measles63 $(82.8 \%)$, were found to be positive and out of 45 cases of chickenpox 36 cases $(80 \%)$ were found to be positive. None of the cases were positive for Widal HBsAg, HIV tests while Leptospira in 2 and Weil felix positivity was detected in 5 cases.

\section{Discussion}

The present study was conducted at the Department of Microbiology, Sir Ronald Ross Institute of Tropical \& Communicable Diseases Hospital, Hyderabad. The study population included 300 hospitalised patients, clinically suspected of fever. This group included only those patients in whom there was no history of drug allergies.

In this study male: female ratio is 1.2:1.In case of Dengue, the commonest age group with febrile rashes is 14-40 years (73.4\%). This observation goes in accordance with studies done by Seema Awasthi et al and Prafulla Dutta et al who reported 58.8\% and 67.1\% of cases respectively [2,3].

In this study, fever $(100 \%)$ is the most common symptom followed by myalgia $97.3 \%$. Similar observation was seen in the study done by Badawy A. Abdul Aziz et al who also reported fever as most common symptom in $100 \%$ cases [4].

In this study, the results of NS1 Antigen (43.7\%) was comparable with the study done by S Datta et al [5]. They proved that early detection of NS1 assay can help in early confirmation and management of vulnerable groups. The study done by Badaway A.

Abdul Aziz et al, found the IgM positivity in $38.5 \%$ and rashin $28.125 \%$ of cases, and in the study by S Dattaet al IgM positivity was reported in $39.1 \%$ of cases while in our study it was $48.1 \%[4,5]$.

A.K Hati et alshowed the seropositivity rate of both IgM+IgG as $12.6 \%$ [6]. Dengue serosurveillance studies may give some idea about advent, intensity, transmission, waxing and warning, and impending epidemic of dengue and DHF.

In the study done by Ahmed Mohamed Ashshi et al, the seropositivity of the cases were $4.2 \%$ for both $\operatorname{IgM}+\operatorname{IgG}$. In this study, the percentage of $\operatorname{IgM}+\operatorname{IgG}$ is found to be $12.3 \%$ indicating the presence of secondary dengue infection [7].

In the study of Neeraja $M$ et al, the adults are affected more due to Dengue fever, $70 \%$ [8]. This findings were similar to our study showing $66 \%$. As per the study done by Kumar A et al in 2010, this pattern was also evident in the study conducted in Kerala [9].

True endemicity will be reached when the adult infection declines and only the new entrants into the population, that is, the children, are affected more by the disease [9].

This shows that the epidemiology of dengue in most endemic regions has shifted to older-age cases, possibly due to extreme climatic or environmental events, prolonged periods of vector control, migration, and urbanization that lead to escalation of mosquito bornevector susceptibility [10].

Chikungunya- In this study, the results of male: female ratio is slightly higher in comparison to the. The ratio of male: female is $1.5: 1$. This probably could be due to more outdoor workers in the population residing in our town, hence more exposure to the vector borne diseases.

The study showed male preponderance, $(60.7 \%)$ which was well correlated with the studies done by Gianandrea Borgherini et al, who also found male preponderance with $56.6 \%$ cases getting affected [11]. However, Debabrata Bandhyopadhyay et al study showed equal preponderance in males and females [12].

The present study showed $57.1 \%$ of cases presenting with rash. Correlate well with the study done by Winfried Taubitzetal [13] Also in study of Galate L.B.et al found $36.85 \%$ of Chickunguniya cases present with rash [14].

Study done by Winfried Taubitz et al during in travellers returning home from countries involved in 


\section{Original Research Article}

epidemics, showed the IgM ELISA confirmed cases as $43.9 \%$ indicating the importance of adequate pre-travel health advice, including dissemination of information about high risk areas and consequent protection from mosquito bites [13]. Also in the study done by Ahmad $\mathrm{N}$ et al, showed IgM result as $96 \%$ and the study by Gianandrea Borgherini et al in Adult patients during 2007 showed the $75 \%$ of $\operatorname{IgM}$ positive cases $[11,15]$.

The serological results goes in accordance with the study done by Supriya Satish Patil et al who conducted a cross sectional study at Kasegaon, Maharastra. A total of 1599 patients were included in the study, of which $62.5 \%$ showed $\operatorname{IgM}$ positivity [16]. In this study, the IgM was positive in $57.1 \%$ of cases.

Chickenpox- The male-to-female ratio in our study is 1.1:1. In the study done by M.P Singh et al shows female preponderance with females percentage of $77.77 \%$, indicating poor vaccination status among the females, in a country like India [17].

The present study showed a contradictory result with the study done by M.P. Singh et a land goes well in accordance to other above-mentioned studies, with male preponderance [17]. The most common age group of patients affected with Chickenpox in our study correlate well the studies showing Singh M.P. et al showing $67 \%$ in age $</=15$ years [17].

Similar presentation is seen in the study done by M.P. Singh. et al. of the 18 laboratory confirmed cases, majority $(67 \%)$ of the affected cases were $<15$ years of age with IgM positivity of $76.5 \%$ [17]. The fact that, chickenpox is more severe in adults than in children, suggest that tropical countries may be at a higher risk of morbidity and mortality due to the disease.

Varicella is one of the leading causes of vaccinepreventable deaths in India. The Indian Academy of Paediatrics-Committee on Immunisation recommends the administration of varicella vaccine in children aged 15 months or older [17]. The presence of vesicles in our study is similar to the study done by M.P. Singh et al showing $66.6 \%$ of cases. In the study done by Singh MP et alin 2011, showed only $10 \%$ of the cases with vesicles, is contradictory with our present study [17].

The IgM results are in concordance with the study done by Singh MP et al showing $80 \%$ of cases. Also in the study done by M.P. Singh et al showed $\operatorname{IgM}$ values as $100 \%$, it has been proposed that the transmission potential of the Varicella Zoster Virus might be adversely affected by a combination of high ambient temperatures and humidity in tropical regions [17].
Measles- The male-to-female ratio in our study is 0.7:1. In our study, ratio of females is more than males, while in study done by Kasper $\mathrm{S}$ et al, showed a female preponderance [18]. In the study done by Amir Mohammed et al, among the pedriatric age group, showed male preponderance of cases, with males as $53 \%$ [19].

In this study, the age most common affected is $>2$ years. (84.2\%) Also in study by Tepebasililet al, similar finding was observed [20]. The study done by Anis-urRehmanetalin contradictory to our study where $>2$ years of age children are commonly affected, indicating the presence of maternal antibodies in the age $<6$ months [21].

Hence Children should go for MR vaccination at the age of 18-24 months with the first booster of DPT/Polio.

In our study secondary complications like Pneumonia is also seen, which correlates well with other studies. In the study done by Kasper S etalin 2009, showed fever $(92.3 \%)$, rash $(92.3 \%)$, coryza $(92.3 \%)$, pneumonia $(62.2 \%)$ and diarrhoea as 38.1\%. 18 In study of Amir Mohammed et alin 2011 showed fever and rash in $100 \%$ of cases with complications like pneumonia in $51 \%$ of cases. 19 Also in study by Deepa K.S etal showed the cases of fever and rash $100 \%$, coryza $83.8 \%$, pneumonia as $12.9 \%$ and diarrhoea $22.5 \%$ of cases [22].

The IgM results $(82.8 \%)$ in our study goes well in accordance with studies. Anne Michel et al the IgM ELISA positivity as $85 \%$ [23]. The study done by Surrender N Gupta et al showed the IgM positivity of $85 \%$ while Hashmi S et al, showed IgM positivity of $90 \%[24,25]$.

\section{Conclusion}

Acute febrile illness comprises infection due to malaria, influenza, leptospirosis, scrub typhus, typhoid fever, and dengue, of which some infections necessitate specific treatment. As antibiotics will be required to treat bacterial diseases, knowing the viral etiology will help in avoiding unnecessary administration of antibiotics.

In view of high mortality and morbidity associated with dengue especially in tropical countries, it is imperative to diagnose the disease during the early phase in order to provide information for appropriate management and avoidance of complications. The NS1 antigen is found together with endothelium, free or soluble in the serum 


\section{Original Research Article}

of patients, and can be detected on days 0-9 after the onset of symptoms. Laboratory diagnosis is important in differentiating primary and secondary infection which helps clinicians to anticipate complications of dengue.

To strengthen measles surveillance through the upcoming Integrated Disease Surveillance Program. Refresher trainings to the workers of the affected areas for proper cold chain maintenance. Information, Education and Communication activities should be targeted towards modifying the help seeking behaviour of mother, education and communication in the district, especially in the measles affected areas

Financial support and sponsorship: Nil.

Conflicts of Interest: There are no conflicts of interest.

\section{References}

1. Harry D. Mckinnon, Thomas Howard. Evaluating the Febrile Patient with a Rash. Am Fam Physician. 2000 Aug 15;62(4):804-816.

2. Seema Awasthi, Vinod Kumar Singh, Santosh Kumar, Ashutosh Kumar, Shyamoli Dutta. The Changing Clinical Spectrum of Dengue Fever in the 2009 Epidemic in North India: A Tertiary Teaching Hospital Based Study. Journal of Clinical and Diagnostic Research. 2012 August, Vol-6(6): 999-1002.

3. Prafulla Dutta, Siraj A. Khan, Jani Borah and Jagadish Mahanta. Demographic and Clinical Features of Patients with Dengue in North eastern Region of India: A Retrospective Cross-Sectional Study during 2009-2011. Journal of Virology \& Microbiology. Vol. 2012 (2012), Article ID 786298, 11 pages

4. Manjunath J. Kulkarni, Vijaya Sarathi, Vikas Bhalla, Deepak Shivpuri \& Usha Acharya. ClinicoEpidemiological Profile of Children Hospitalized with Dengue. Indian J Pediatr (2010) 77:1103-1107.

5. Datta S, Wattal C. Dengue NS1 antigen detection: a useful tool in early diagnosis of dengue virus infection. Indian J Med Microbiol. 2010 Apr-Jun;28(2):107-10. doi: 10.4103/0255-0857.62484.

6. Hati AK. Dengue serosurveillance in Kolkata, facing an epidemic in West Bengal, India. J Vector Borne Dis. 2009 Sep;46(3):197-204.

7. Ahmed Mohamed Ashi. The prevalence of dengue virus serotypes in asymptomatic blood donors reveals the emergence of serotype 4 in Saudi Arabia. Virology Journal 2017;14:107
8. Neeraja M, Lakshmi V, Teja VD, et al. Sero diagnosis of dengue virus infection in patients presenting to a tertiary care hospital. Indian J Med Microbiol. 2006 Oct;24 (4):280-2.

9. Ashwini Kumar, Chythra R Rao, Vinay Pandit, Seema Shetty, Chanaveerappa Bammigatti, Charmaine Minoli Samarasinghe. Clinical Manifestations and Trend of Dengue Cases Admitted in a Tertiary Care Hospital, Udupi District, Karnataka. Indian Journal of Community Medicine 2010;July 35(3):386-390.

10. Cucunawangsih, Lugito NP, Kurniawan A. Immunoglobulin $\mathrm{G}$ ( $\mathrm{IgG}$ ) to $\mathrm{IgM}$ ratio in secondary adult dengue infection using samples from early days of symptoms onset. BMC Infect Dis. 2015 Jul 21;15:276. doi: 10.1186/s12879-015-1022-9.

11. Borgherini G, Poubeau P, Staikowsky F, et al. Outbreak of chikungunya on Reunion Island: early clinical and laboratory features in 157 adult patients. Clin Infect Dis. 2007 Jun 1;44(11):1401-7. Epub 2007 Apr 18.DOI:10.1086/517537

12. Debabrata Bandyopadhyay, Sudip Kumar Ghosh. Mucocutaneous features of Chikungunya fever: a study from an outbreak in West Bengal, India.IJD. 2008;47 (11): 1148-1152.

13. Winfried Taubitz, Jakob P Cramer, Anette Kapaun, Martin Pfeffer, Christian Drosten, Gerhard Dobler, Gerd D Burchard, Thomas Löscher. Chikungunya fever in travelers: clinical presentation and course. An Official Publication of the Infectious Diseases Society of America 2007; July 1, 45 (1): e1-4.

14. Galate LB, Agrawal SR, Shastri JS, et al. Chikungunya Fever Among Patients with Acute Febrile Illness Attending a Tertiary Care Hospital in Mumbai. J Lab Physicians. 2016 Jul-Dec;8 (2):85-9. doi: 10.4103/0974-2727.180787.

15. Ahmad N. Chikungunya Fever - epidemic in rural maharashtra. Indian J Community Med. 2009 Oct;34(4):372-4. doi: 10.4103/0970-0218.58409.

16. Patil SS, Patil SR, Durgawale PM, et al. A study of the outbreak of Chikungunya fever. J Clin Diagn Res. 2013 Jun;7(6): 1059-62. doi: 10.7860/JCDR/2013/ 5330.3061. Epub 2013 Apr 10.

17. Singh MP, Chandran C, Sarwa A, et al. Outbreak of chickenpox in a Union Territory of North India. Indian J Med Microbiol. 2015 Oct-Dec;33(4):524-7. doi: 10.4103/0255-0857.167335. 


\section{Original Research Article}

18. Kasper S, Holzmann H, Aberle SW, et al. Measles outbreak in Styria, Austria, March-May 2009. Euro Surveill. 2009 Oct 8;14(40). pii: 19347.

19. Amir Muhammad, Muhammad Irshad, BehramKhan. A comparative study of measles complications in vaccinated versus non-vaccinated children. JPMI 2011;25 (1): 04 - 08.

20. Tepebaşili I, Caksen H, Odabaş D, et al. Measles is still a severe problem in eastern Turkey. J Emerg Med. 2004 Jul;27(1):87-8.

21. Anis-ur-Rehman, Siddiqui TS, Idris M. Clinical outcome in measles patients hospitalized with complications. J Ayub Med Coll Abbottabad. 2008 Apr-Jun; 20 (2):14-6.

22. Deepa K.S. Clinical Profile of Measles in Children admitted to a Rural Tertiary Care Hospital. Journal of
Evolution of Medical and Dental Sciences 2015; 4(46): 7995-7999.

23. Michel Y, Saloum K, Tournier C, et al. Rapid molecular diagnosis of measles virus infection in an epidemic setting. J Med Virol. 2013 Apr;85(4):723-30. doi: 10.1002/jmv.23515. Epub 2013 Jan 30.

24. Surender N Gupta, Naveen Gupta, Shivani Gupta. A Mixed Outbreak of Rubeola-Rubella in District Kangra of Northern India. Journal of Family Medicine and Primary Care 2013, 2 (4): 354-9.

25. Hashmi S, Singh A K, Rawat V, Kumar M, Mehra A K, Singh R K. Measles outbreak investigation in Dwarahat block of District Almora, Uttarakhand. Indian J Med Microbiol2015;33:406-9.

\section{How to cite this article?}

Sultana A., M.L. Kavitha Latha Serological profile of febrile rash in patients at a tertiary care hospital in Telangana. Trop J Path Micro 2018;4(7):545-550.doi:10.17511/jopm.2018.i07.11. 